\title{
İleri Yetişkinlerle Çalışan ve Araştırma Yapan Psikologların Dikkat Etmesi Gereken Etik Konular
}

\author{
Şule Selçuk \\ Kastamonu Üniversitesi
}

\begin{abstract}
Özet
Bu yazının amacı, ileri yetişkinlere psikolojik hizmet verme ve ileri yetişkinlerle araştırma yürütme sürecinde dikkat edilmesi gereken etik konuları gözden geçirmek ve bu konulardaki etik farkındalığı artırmaktır. Bu bağlamda yeterlik, özerklik, bilgilendirilmiş onam, gizlilik ve yaşlı istismarı ile ilgili alanyazında öne çıkan etik konu ve tartışmalara değinilmiş ve bazı önerilere yer verilmiştir. İleri yetişkinlerle çalışan ve araştırma yapan psikologların, (a) ek bir takım bilgi ve becerilere sahip olmaları, (b) ileri yetişkin ile aile üyelerinin istekleri uyuşmadığında ya da ileri yetişkinin bilişsel becerilerinde belirgin bir gerileme olduğunda, ileri yetişkinin özerkliğini mümkün olduğunca koruyan ve zarar verme olasılığını en düşük düzeye indiren çözüm önerileri üretmeleri, (c) bilgilendirilmiş onam alırken ileri yetişkinlerin araştırma ya da tedaviyi tam anlamıyla kavrayıp kavramadıklarına özen göstermeleri, (d) daha genç danışanlara sağladıkları tam gizliliği ileri yetişkinlere de sağlamaları ve (e) yaşlı istismarı ile ilgili yasal düzenlemeler ve etik ikilemlere hakim olmaları gibi birçok etik gereklilik ele alınmıştır.
\end{abstract}

Anahtar kelimeler: Etik konular, ileri yetişkinler, psikolojik hizmet, araştırma

\begin{abstract}
The aim of the present paper is to review noteworthy ethical issues associated with providing psychological services and conducting research with older adults, and thus to expand ethical awareness about these issues. In this regard, prominent ethical issues and discussions in the literature related to competence, autonomy, informed consent, confidentiality, and elder abuse and some suggestions regarding these issues were addressed. Various ethical necessities for psychologists working with older adults were discussed, such as (1) to have additional knowledge and skills, (2) to offer solutions that best maintain the autonomy of older adults and minimize the possibility of harm when the demands of the older adult and family members are not compromised or if there is a severe cognitive decline, (3) to pay particular attention whether or not older adults properly understand the research or treatment while obtaining informed consent, (4) to ensure full confidentiality for older adults that they provide for younger adults, and (5) to have sufficient knowledge about legislative regulations and ethical dilemmas regarding elder abuse.
\end{abstract}

Keywords: Ethical issues, older adults, psychological services, research

Yazar Notu: Yazar, önerileri ve destekleri için Prof. Dr. Zehra Uçanok’a ve Prof. Dr. İhsan Dağ’a teşekkür eder.

Yazışma Adresi: Arş. Gör. Şule Selçuk, Kastamonu Üniversitesi, Fen Edebiyat Fakültesi, Psikoloji Bölümü, Kuzeykent Yerleşkesi, 37150, Kastamonu.

E-posta: sselcuk@kastamonu.edu.tr

Gönderim Tarihi: 05.03.2017

Kabul Tarihi: 31.08 .2019 
Psikoloji alanında etik ilkeler, psikologların benimsemesi gereken ortak değerleri ortaya koyar ve psikologlara mesleki yaşamlarında rehberlik eder (TPD Etik Yönetmeliği, 2004). Ayrıca etik ilke ve yönetmelikler toplumun psikologlara güven duymasını sağlar ve olası etik ihlallere karşı hem psikologları hem de hizmet alanları korur (Oakland ve ark., 2012; TPD Etik Yönetmeliği, 2004). Psikoloji biliminin doğrudan insan yaşamı ile ilgili olması, bu alandaki etik ilkelerin varlığını ve psikologların etik ilke ve standartlara uygun hareket etmesini daha da önemli hale getirmektedir. Türkiye'de 2004 yılında yayınlanan TPD Etik Yönetmeliği (2004), psikologların izlemesi gereken etik ilke ve standartları içermektedir ve akademik alanda ve uygulama alanında çalışan psikologlara rehberlik eden başlıca kaynaktır. Ancak sözü edilen yönetmelikte ileri yetişkinlerle çalışan ya da araştırma yapan psikologlar için özel etik standartlar bulunmamaktadır. Benzer şekilde, APA'nın (2004; 2014) ileri yetişkinlerle çalışan psikologlar için hazırladığ1 bir kılavuz olmasına rağmen bu konuya özel geliștirilmiş etik standartlar henüz bulunmamaktadır.

TPD Etik Yönetmeliği'nin dişında, Türkiye'de psikoloji alanında uygulama, araştırma ve yayın ile ilgili etik konu ve tartışmaları ele alan sınırlı sayıda makale bulunmaktadır (örn., Aycan, 1998; Çakmak, 2018; Değirmencioğlu ve Demirutku, 1999; Ertan Kaya, 2017; Eskin, 2000; Korkut, Müderrisoğlu ve Tanık, 2006; Sayıl ve Y1lmaz, 2001; Sümer, 1998; Türk Psikologlar Derneği, 1999). Bunun yanı sıra, 2007'de yayınlanan Türk Psikoloji Bülteni'nin teması "Psikolojide Araştırma, Yayın ve Uygulama Etiğì" olarak belirlenmiştir. Bu bültende farklı etik konuları (örn., psikoterapi etiği, araştırma etiği, deney hayvanları ile ilgili etik konular) içeren makaleler (örn., Köse, 2007; Guzey, 2007; Şenyüz, 2007) bulunmakla birlikte doğrudan ileri yetişkinlik dönemini içeren herhangi bir kaynağa ulaşılamamıştır. Benzer bir durum uluslararası yazında da gözlenmektedir. Dolay1sıyla, bu derleme makalesinde ileri yetişkinlere psikolojik hizmet veren ve ileri yetişkin yaş grubuyla araştırma yapan profesyonellerin dikkat etmesi gereken belirli etik konular ele alınarak alanyazındaki bu boşluğun doldurulması hedeflenmiștir.

Tıp ve teknolojideki gelişmelerle birlikte yaşam beklentisinin ve ileri yetişkin nüfusun arttığ 1 bilinmektedir. Ayrıca ileri yetişkin nüfusunun toplam nüfusa oranının artmaya devam edeceği öngörülmektedir. Türkiye İstatistik Kurumu'nun (TÜİK, 2013) verilerine göre Türkiye'de doğumdaki yaşam beklentisi ortalama 78 yıldır. (Kadınların [80.7] yaşam beklentisi erkeklerden [75.3] daha yüksektir). TÜİK'in 2013 - 2075 yılları için yaptığ1 nüfus projeksiyonlarına göre, 2013 yılındaki nüfusun \%7.7'sini 65 yaş ve üstündeki bireyler oluştururken (60 yaş ve üstü nüfus, \%11.3'ünü oluşturmaktadır), 2075 yılında bu oranın \%27.7'ye çıkması beklenmektedir (60 yaş ve üstü nüfus için bu oran \%34'tür). Bu demografik değişikliklere bağlı olarak psikoloji alanında ileri yetişkinlerle yürütülen araştırmalara olan ilgi de giderek artmaktadır. Amerikan Psikologlar Birliği İleri Yetişkinler Broşürü Çalışma Grubu'nun (1998) da vurguladığı gibi ileri yetişkinlere psikolojik hizmet sunan psikolog sayısı giderek artacaktır. Tüm bu gelişmelere bağlı olarak, hem uygulama hem de araştırma alanında, ileri yetişkinlerle çalışırken dikkat edilmesi gereken etik konulara yönelik farkındalık kazanmanın önemi aşikardır.

Alanyazın incelendiğinde genellikle bilişsel bozuklukları olan ileri yetişkinlerle yapılan araştırmalarda dikkat edilmesi gereken etik konuların ön plana çıktığı görülmektedir (Schwiebert, Myers ve Dice, 2000). Fakat bilişsel becerileri açısından ileri yetişkinler arasında önemli bireysel ayrılıklar olduğu, bazı bilişsel becerilerin (örn., sözel beceri) daha ileri yaşlarda da korunabildiği dikkate alınarak (bkz. Schaie, 1996) bu yazıda ilgili etik konular bilişsel bozukluktan bağımsız olarak daha geniş kapsamlı ele alınmaya çalıșılmıștır. Makalede sırasıyla yeterlik, özerklik, bilgilendirilmiş onam, gizlilik ve yaşlı istismarıyla ilgili etik konulara değinilmiştir.

\section{Yeterlik}

İleri yetişkinlerle çalışan psikologların dikkat etmesi gereken en önemli etik konulardan biri yeterliktir. İleri yetişkinlerle ve/veya onların aileleriyle çalışan psikologların yeterli olarak hizmet verebilmeleri için ek bir takım bilgi ve becerilere gereksinim duydukları belirtilmektedir (Karel, 2011). Bu noktada, ileri yetişkin yaş grubunun homojen bir grup olmadığ ber, 2013) sahip olmanın oldukça önemli olduğu söylenebilir. Örneğin, 80 yaşında bir birey fiziksel ve psikolojik açıdan oldukça yüksek işlevsellik gösterirken, 65 yaşında başka bir bireyin birçok sağlık sorunu olabilir. Pek çok çalışmadan sonra, genç yetişkin ve orta yetişkin yaş grubuyla karşılaştırıldığında, ileri yetişkin grubunda daha fazla bireysel farkl1lık olduğu görülmüştür. Bu noktadan hareketle araştırmacılar ileri yetişkinlik dönemini kronolojik yaş temelinde, genç-yaşl1 (65-74), yaşl1-yaşlı (75-84) ve en yaşl1-yaşlı (85 ve üstü) olmak üzere kategorilere ayırmanın iyi bir yol olabileceğini öne sürmüşlerdir. Genç-yaşl1ların, yaşl1-yaşlı ve en yaşl1-yaşlı yetişkinlere göre fiziksel olarak daha iyi durumda oldukları ve duyusal ve bilişsel becerilerinde daha az gerileme olduğu, dolayısıyla genç-yaşlıların orta yetişkinliğin son dönemindeki bireylere oldukça benzediği belirtilmektedir (Erber, 2013). Yaşl1-yaşlılarda duyusal, algısal ve bilişsel işlevlerdeki gerilemenin daha belirgin hale geldiği bilinmektedir. En fazla sağlık problemi yaşayan ve ilgili hizmetlere en fazla ihtiyaç duyan grup ise en yaşl1-yaşlılardır. Bu dönemde bilişsel beceri ve öğrenme potansi- 
yelinde önemli düzeyde gerileme ve kronik hastalıklarda artış gibi olumsuz durumların görülme olasılığı daha yüksektir (Erber, 2013). Genç-yaşlı grubun özellikleri daha genç yaş grubundakilere benzer olduğundan, yetişkinlerle çalışan psikologların bu gruba yeterli bir hizmet sunabilme olasılığının görece daha yüksek olduğu belirtilmektedir. Ancak yukarıda da ifade edildiği gibi, özellikle yaşl1-yaşlı ve en yaşl1-yaşlı gruplarındaki bireylerin diğer yetişkin yaş gruplarından fiziksel ve psikolojik olarak oldukça farklılık göstermeleri nedeniyle bu gruplar için, yetişkinlere yönelik klinik ya da danışmanlık psikolojisi eğitimi almak tek bașına yeterli değildir. Dolayısıyla doğrudan bu gelişimsel döneme yönelik ek bilgi ve beceri kazanmak kaçınılmaz görünmektedir (Knight, Karel, Hinrichsen, Qualls ve Duffy, 2009; Molinari ve ark., 2003; Qualls, Segal, Norman, Niederehe ve Gallagher-Thompson, 2002).

APA üyeleriyle yapılan bir anket çalışmasında üyelerin \%69'u hali hazırda ileri yetişkinlere hizmet verdiklerini ve \%40'1 ileri yetişkinlerle daha fazla çalışmak istediklerini belirtmişlerdir. Ancak bu üyelerin \%58'i yeterlik kapsamında ve etik olarak hizmet verebilmek için daha fazla eğitime ihtiyaçları olduğunu ifade etmişlerdir (Qualls ve ark., 2002). Bu anketin verilerine dayanarak, Qualls ve arkadaşları (2002), ileri yetişkinlere psikolojik hizmet sunan ya da sunmayı düşünen psikologların deneyimleri ve bu alanda çalışmaya yönelik bağlilıklarına göre yaşlanma süreci, bu süreçte yaşanan güçlükler ve tedaviler gibi konularda giriş düzeyinde ya da daha ileri düzeyde eğitim almaları gerektiğini belirtmişlerdir. Benzer şekilde, McGuire (2009) ileri yetişkinlere ruh sağlığg1 hizmeti sunanların, etik standartlara uygun ve etkili bir hizmet verebilmeleri için yaşlanma süreci ve yaşlanma sürecinin ileri yetişkinlerin yaşamlarını nasıl etkilediği konularında bilgili olmaları gerektiğini vurgulamaktadır. Nitekim aşağıda değinilen APA'nın yayınladığı kılavuzun 21. maddesinde psikologlar, ileri yetişkinlerle çalışmaya yönelik bilgi ve becerilerini geliştirmeleri ve bu konuda eğitim, süpervizyon vb. almaları için teşvik edilmektedirler (APA, 2004; 2014). Bununla ilişkili olarak, ileri yetişkinlerle çalışan alandaki deneyimli psikologlar, geropsikoloji alanında eğitim fırsatlarının artırılması gerektiğini dile getirmektedirler (Bush, Allen, Heck ve Moye, 2015). İleri yetişkin nüfusundaki artışa rağmen çok az psikoloğun ileri yetişkinlere hizmet verme konusunda uzmanlaştı̆̆ 1 ve birçok psikoloğun özel bir eğitim ve süpervizyon almadan ileri yetişkinlere hizmet verdiği dikkate alındığında (Hoge, Karel, Zeiss, Alegria ve Moye, 2015), yeterlik ilkesi ile ilgili bu gerekliliklerin yerine getirilmediği söylenebilir.

APA, 2004 yılında ileri yetişkinlerle klinik alanda çalışan psikologlar için, APA Etik Yönetmeliği’ne ve APA'nın diğer politikalarına uygun olarak hazırlanan ve uyulması zorunlu olan standartlardan ziyade erdem gereği olan hedefleri (aspirational goals) içeren "İleri Yetişkinlerle Psikolojik Uygulama için Kılavuz” başlıklı bir metin yayınlamıştır (APA, 2004). 2014 yılında güncellenen bu k1lavuz (APA, 2014), altı bölümden oluşmakta ve psikologları pek çok açıdan ek bilgi edinmeleri ve farkındalık kazanmaları konusunda teşvik etmektedir. $\mathrm{Bu}$ konulardan bazıları, (a) yaşın ilerlemesiyle birlikte ortaya çıkan gelişimsel değişiklikler, (b) hem ileri yetişkinlerin özellikleri ve bireysel farklılıklar hem de bu yaş grubunda değerlendirme amaçlı kullanılan araçlar konusunda bilgi sahibi olmanın gerekliliği ve (c) psikoloğun ileri yetişkinlere yönelik tutumlarının farkında olmasının önemidir (ayrıntılı bilgi için bkz. APA, 2004; 2014). Örneğin, bu kılavuzda ilgili psikologların, ileri yetişkinlere yönelik belirli kalıp yargıların (örn., ileri yetişkinler sosyal olarak yalıtılmışlardır, bu dönemde depresyon olasılığ1 yüksektir, bilişsel becerilerde engellenemez gerilemeler olur) farkında olmalarının ve bu kalıp yargıların gerçeği yansıtmadığının farkındalığıyla hareket etmelerinin önemi vurgulanmaktadır. Bu bağlamda yürütülen araştırmalar, bu kalıp yargıların aksine yaşla birlikte bazı bilişsel becerilerde gerilemeler olsa da belirli bilişsel becerilerin korunduğunu ya da bu becerilerde çok az bir gerileme olduğunu (bkz., Schaie, 1996) göstermektedir. Ayrıca ileri yetişkinlikte iyi oluş düzeyinin genç yetişkinlerden daha yüksek olduğu bulunmuştur (Charles ve Carstensen, 2009). Buna ek olarak, ileri yetişkinlikte sosyal ilişki ağındaki azalmanın yaşlılığın getirdiği belirli kısıtlamaların (örn., fiziksel işlevselliğin gerilemesi, sosyal rollerde azalma) bir sonucu olarak ortaya çıkmadığ1 belirtilmektedir. İleri yetişkinlerin sadece keyif aldıkları ilişkileri devam ettirme motivasyonuyla hareket ederek kasitlı olarak böyle bir daralmaya gittikleri ortaya konmuştur. Dolayısıyla sosyal ilişki ağında gözlenen bu daralmanın, sanılanın aksine ilişkilerden daha yüksek doyum alabilmeyi sağladığı ifade edilmektedir (Charles ve Carstensen, 2009). Psikoloğun bu bilgilere sahip olmas1, belirli sorunların yaş ile ilişkili normatif değişikliklerin doğal bir sonucu olduğu önyargısından kurtulmasını ve daha objektif bir bakış açısıyla durumu değerlendirmesini sağlayabilmesi açısından oldukça önemlidir. Ayrıca ileri yetişkinlik döneminde normatif ve normatif olmayan değişiklikler, bu dönemde yaygın olarak görülen hastalıklar (örn., eklem iltihabı ve damar hastalıkları) ve kullanılan ilaçlar konusunda yeterli bilgiye sahip olmanın, belirtilen ya da tespit edilen sorunların neden kaynaklandığını (ruhsal ya da fiziksel) anlamada yardımcı olabileceği belirtilmektedir (Barnett ve Quenzel, 2017). Bunun yanı sıra, Molinari ve arkadaşları (2003) da iki düzeyde yeterlik tanımlamıştır. Birinci düzey yeterlik için önerilen bilgi ve beceriler, ileri yetişkinlere genel düzeyde psikolojik hizmet sunan psikologlar içindir. İkinci düzey ye- 
terlik için yapılan öneriler ise bu alanda daha uzman olan psikologlar için sunulan önerilerdir. Dolayısıyla bu makale de ileri yetişkinlerle çalışan ya da çalışmayı düşünen psikologların yeterlik konusunda kendilerini değerlendirmek ve hangi açılardan daha fazla bilgi ve beceri edinmeye ihtiyaç duyduklarını tespit etmek için yararlanabilecekleri bir kaynak olabilir. Alanyazında sıkça değinilen ve ileri yetişkinlerle çalışan psikologların kullanabileceği diğer bir kaynak da Knight ve arkadaşlarının (2009) sundukları "The Pikes Peak" modelidir. Bu modelde ileri yetişkinlerle çalışan psikologların yeterli bir şekilde psikolojik hizmet verebilmelerinde önemli olan tutum, bilgi ve beceriler kapsamlı olarak ele alınmaktadır. Buna ek olarak "Pikes Peak Geropsikoloji Bilgi ve Becerisini Değerlendirme Aracı" (Karel, Emery, Molinari ve CoPGTP Task Force on the Assessment of Geropsychology Competencies, 2010) psikologların kendi yeterliklerini değerlendirebilecekleri önemli bir kaynaktır. Psikologlar bu değerlendirme aracını kullanarak hangi konularda yeterli olduklarını ve hangi konularda bilgi edinmeye ya da eğitim almaya ihtiyaç duyduklarını daha açık bir şekilde görebilirler (Karel ve ark., 2010).

\section{Özerklik}

İleri yetişkinlerle çalışan psikologların karşılaştığ1 en yaygın etik ikilemlerden biri danışanın özerkliği ile psikoloğun yararlı olması-zarar vermemesi ve danışanın özerkliğini koruma ile danışan-psikolog ilişkisini koruma arasındadır (Bush ve ark., 2015; Fitting, 1986; Karel, 2011). Bu tür ikilemler, ileri yetişkinin isteği ile sağlik hizmeti verenlerin ya da aile üyelerinin istekleri uyuşmadığ 1 durumlarda ortaya çıkmaktadır. Ayrıca danışanın başta bilişsel olmak üzere (örn., demans) görme duyusu gibi belirli işlevlerinde bozulma olduğunda ya da majör depresyon gibi ciddi bir hastalık veya ölümcül bir hastal1k söz konusu olduğunda görülmektedir (Fitting, 1986; Karel, 2011; Schwiebert ve ark., 2000; Woods ve Pratt, 2005). Bu ikilemlerin ortaya çıkma nedeni, bu tür durumların kişinin kendi güvenliği ve iyilik hali gibi konularda karar verme becerisini etkilemesidir (APA, 2004). İleri yetişkinlerin karar verme kapasitelerinin değerlendirilmesi zordur ve bu kapasite kısa bir zaman aralığında oldukça değişebilmektedir. Bu nedenle ileri yetişkinlerin bilişsel işlevselliğinin tekrarlı olarak değerlendirilmesi ve düzenli olarak izlenmesi gerekebilir (Scheiderer, 2012). Bu noktada, ileri yetişkinlerin önemli bir kısmının da karar verme konusundaki işlevselliklerinin oldukça iyi durumda olduğunu unutmamak gerekir. Psikologlar bu değerlendirmeyi yaparken ileri yetişkinlere yönelik bazı kalıp yargıları nedeniyle (örn., yaşın ilerlemesiyle birlikte bilişsel becerilerde gerileme olması kaçınılmazdır) onların karar verme kapasitelerini azımsayabileceklerinin farkında olmalıdırlar (Karel, 2011).
APA'nın (2004; 2014) ilgili k1lavuzunun 19. maddesinde danışanın özerkliği ile psikoloğun yararlı olması ve zarar vermemesi arasındaki etik ikileme değinilmektedir. Bu ikilem, özellikle uzun süreli kurum bakımı altında ve ağır zihinsel hastalıkları olan ileri yetişkinler söz konusu olduğunda ortaya çıkmaktadır. Kurumlarda yaşayan ileri yetişkinlerin daha esnek ortamlarda yaşama isteği ile aileleri ya da ruh sağlığ çalışanlarının ileri yetişkinin kurumda kalması gerektiği yönündeki görüşü çatışabilmektedir (APA 2004; 2014). Schwiebert ve arkadaşları (2000) danışanın, gittikçe kötüye giden durumuna rağmen güvenli olmasa da evde yalnız yaşama ya da kurum bakımına alınmama konusunda 1srarcı olabileceği örneğini vermektedir. Bu gibi durumlarda danışan hem kendinin hem de başkalarının güvenliğini tehlikeye atmaktadır (örn., ocağı açık unutma). Bu nedenle psikolog, danışanın ve başkalarının zarar görmesini engelleme (yararlı olmak, zarar vermeme ilkesi) ile danışanın kararına sayg1 duyma (özerklik ilkesi) arasında bir ikilem yaşayabilmektedir. Böyle durumlarda, psikoloğun özerkliği en üst düzeyde sağlayacak ve zarar verme olasılığını en düşük düzeye indirecek şekilde davranması önemlidir (Schwiebert ve ark., 2000). Bir başka deyişle, Karel'in (2011) belirttiği gibi, ileri yetişkinin isteği ile onun için en iyi olan durum arasında bir denge kurmak gerekmektedir. Fitting (1986) aile üyeleri ve danışanın istekleri uyuşmadığ durumda, psikoloğun danışan ve aile üyeleri ile birlikte görüşebileceğini ifade etmektedir. Bu görüşmelerde psikolog, aile ilişkilerini değerlendirebilir ve problemi aile ilişkileri bağlamında ele alabilir. Örneğin, bu görüşmeler sırasında psikolog, aile üyelerinin danışanı olası bir zarardan korumak istediklerini anlayabilir, dolayısıyla da probleme danışanın anlattığından daha farklı bir şekilde yaklaşabilir. Ayrıca danışanın karar verme kapasitesinin yeterli olduğu düşünülüyor ise özerkliğine sayg1 duyulması gerektiğini savunmaktadır. Bu durumda, danışan ve aile üyeleriyle birlikte yapılan görüşmelerde danışanın özerkliğini üst düzeyde tutacak ve ailenin de isteklerini karşılayabilecek ortak bir çözüm yolu bulunabileceğini (örn, danışanın evinde koruyucu birtakım fiziksel önlemler almak) belirtmektedir. Bu öneriler, belirli vakalarda işlevsel olabilirken bazılarında yol gösterici olmayabilir. Fitting (1986) yukarıda örneklendirilen durumlarda sadakat, özerklik ve yararlı olma-zarar vermeme ilkelerinden hangisinin ön planda olması gerektiğine karar verirken, ilgili etik standartların yanı sıra bireyin sağlık durumu, psikolojik işlevselliği ve karar verme kapasitesi ile ilgili değerlendirmenin önemine dikkat çekmektedir. Ayrıca ileri yetişkinlerin oldukça heterojen bir grup olması nedeniyle, ait oldukları yaş grubunun özellikleri temel alınarak genel düzeyde bir yargıyla hareket edilmemesini ve her ileri yetişkinin biricik olarak değerlendirilmesinin gerekliliğini vurgulamaktadır (Fitting, 1986). 


\section{Bilgilendirilmiş Onam}

İleri yetişkinlerle çalışan psikologların dikkat etmesi gereken etik konulardan bir diğeri de tedavi ya da araştırmaya katılım için alınan bilgilendirilmiş onamdır (McGuire, 2009; Schwiebert ve ark., 2000). Bilgilendirilmiş onam alınırken ileri yetişkinlerin araştırma ya da tedaviyi tam anlamıyla kavrayıp kavramadıklarına ayrı bir özen gösterilmelidir (McGuire, 2009). Özellikle Alzheimer gibi zihinsel becerilerin giderek bozulduğu hastalıklarda ileri yetişkinin onam verip veremeyeceği konusunda bir değerlendirme yapmak zordur (Schwiebert ve ark., 2000). Bu nedenle gerekli görülen durumlarda, ileri yetişkinden söz konusu tedavi ya da çalışma hakkında verilen bilgileri kendi cümleleriyle tekrar etmesi istenerek geçerli bir onam almak mümkün olabilir (Locher, Bronstein, Robinson, Williams ve Ritchie, 2006; McGuire, 2009).

Yukarıda değinildiği gibi, ileri yetişkinlerin sağlıklarının ve bilişsel işlevlerinin giderek kötüleştiği durumlarda gerileme ve bozulmaların seyri ve hizı konusunda da bireysel farkl11lklar söz konusudur. Bu nedenle, ileri yetişkinin tam olarak ne zaman bilgilendirilmiş onam veremeyeceğine karar vermek oldukça zorlayıcı bir sorundur (Fitting, 1986; Schwiebert ve ark., 2000). Dolayısıyla psikologların, ileri yetişkinlerin bilişsel beceri ve bozukluklarını değerlendiren ölçme araçlarının bu yaş grubuna özgü sınırlılıkları konusunda bilgi sahibi olmaları gerekmektedir (Schwiebert ve ark., 2000). Karar verme kapasitesi konusunda şüpheler varsa ve psikolog bu konuda karar verecek uzmanlığa sahip değilse, ileri yetişkin başka bir uzmana yönlendirilerek karar verme kapasitesi değerlendirilebilir (Molinari ve ark., 2003). $\mathrm{Bu}$ süreçte unutulmaması gereken noktalardan biri de belirli bir alanda becerileri gerileyen ya da bozulan ileri yetişkinlerin işlevselliklerinin diğer alanlarda devam edebildiği ve karar verme kapasitelerini koruyabildikleri gerçeğidir. Dolayısıyla bu durum göz önünde bulundurularak dikkatli bir değerlendirme yapılması gerekmektedir (APA, 2004; 2014).

APA'nın ilgili etik kılavuzunun 19. maddesinde, aile üyeleri tarafindan terapiye getirilen ileri yetişkinlerin, bu kararı ailelerinin etkisi altında olmadan özerk olarak verdiklerinden emin olunması gerektiği belirtilmektedir (APA, 2002; 2014). TPD Etik Yönetmeliği'nin (2004) 7.1 no'lu maddesinde de danışanın kendi kararını veremeyecek durumda olması koşulunda, velinin ya da velayet sahibinin onayının alınması ve danışanın özerkliğinin mümkün olduğunca gözetilmesi gerektiği bildirilmektedir. Dolayısıyla ileri yetişkinin bilişsel bozukluğu olduğunda ya da karar verme kapasitesini olumsuz anlamda etkileyen durumlar söz konusu ise (ileri yetişkinlerin bilişsel becerilerinde bilgilendirilmiş onam veremeyecek düzeyde ciddi bir gerileme/bozulma varsa) velayet sahibinin bilgilendirilmiş onamı alınmalıdır. $\mathrm{Bu}$ noktada, velayet sahibi ile danışan arasında çıkar çatışmasının olmadığından, dolayısıyla velayet sahibinin ileri yetişkin için en iyisinin ne olacağını düşünerek hareket ettiğinden emin olunmalıdır (Beck ve Shue, 2003; Bush ve ark., 2015; Resau 1995).

Bilişsel becerilerde gerileme olduğu durumlarda bilgilendirilmiş onam alma konusunda önerilen diğer bir çözüm yolu "çift onam"dır. Bu çözüm, Resau (1995) tarafindan Alzheimer hastalarıyla çalışanlar için önerilmiştir. Çift onamda, duygu ve düşüncelerini ifade etme becerisini bir dereceye kadar koruyan ancak tam anlamiyla onam verecek düzeyde olmayan Alzheimer hastalarının velayet sahibinden bilgilendirilmiş onam, kişinin kendisinden de izin (assent) alınmaktadır. Böylece, özerkliğe saygı ilkesi doğrultusunda hareket edilmiş ve kişi olabildiğince onam sürecinin içine dahil edilmiş olur (Resau, 1995).

İleri yetişkinlerle yürütülecek bir araştırma planlanıyorsa, yukarıdaki noktalara ek olarak şu konulara da dikkat çekilmektedir: (a) araştırmanın, bağımsız bir inceleme komisyonunda yer alan ve ileri yetişkinlik dönemi konusunda bilgisi olan uzmanlar tarafindan incelenmesi, (b) araştırmanın olası yarar ve zararlarının tartılması ve (c) olası zararların nasıl azaltılabileceğinin belirlenmesi gerekmektedir (Schwiebert ve ark., 2000). İleri yetişkinlerle araştırma yapılırken dikkat edilmesi gereken bir diğer konu da terapötik yanlış kanıdır. Özellikle evden çıkamayan ya da eve bağımlı (homebound) ileri yetişkinlerle araştırma yapılırken, ileri yetişkinlerin bir tür tedavi ya da bakım alacaklarını düşünme olasılıkları oldukça yüksektir. Bu nedenle bilgilendirilmiş onam alınırken araştırma kapsamında herhangi bir tedavi verilmeyeceği açıkça belirtilmelidir (Locher ve ark., 2006). Bunun yanı sıra, evden çıkamayan ileri yetişkinler, genel olarak sağlık çalışanları gibi aracılar ile çalışmaya dahil edildiklerinden, sağlık çalışanına yönelik beklentileri nedeniyle (örn., araştırmaya katılarak sağlık çalışanını memnun etmek) ya da yalnız oldukları ve sağlık hizmetine daha kolay ulaşabileceklerini düşündükleri için çalışmaya katılmayı kabul edebilirler (Locher ve ark., 2006). Bu nedenle, Locher ve arkadaşları (2006) evden çıkamayan ileri yetişkinlerle araştırma yürütenlerin, bu kişilerin araştırmaya "zorunlu" olarak katılma olasılıkları konusunda daha dikkatli olmaları gerektiğini hatırlatmakta ve iki aşamalı bilgilendirilmiş onam önermektedir. İki aşamalı bilgilendirilmiş onamın ilk aşamasında sağlık çalışanı, araştırma ekibine öneriyi yapmadan önce potansiyel katılımcıdan (araştırmaya önerilmesi için) yaz1lı bilgilendirilmiş onam alır. İkinci aşamada ise araştırmacılar, araştırmaya katılım için önerilmeyi kabul eden katılımcıların evine giderek araştırmaya katılım için bilgilendirilmiş onam alır (Locher ve ark., 2006). 


\section{Gizlilik}

İleri yetişkinlerle çalışan psikologların karşılaşabilecekleri etik ikilemlerin bir kısmı da gizlilikle ilgilidir ve bu konudaki ikilemlerin özerklikle ilgili etik tartışmalarla yakından ilişkili olduğu söylenebilir. TPD Etik Yönetmeliği'ne (2004) göre psikoterapi, psikolojik değerlendirme ya da araştırmaya başlamadan önce gizliliğin sınırları belirtilmeli ve olası katılımcı ya da danışan kararını buna göre verebilmelidir. Bu doğrultuda, ileri yetişkinler söz konusu sınırlar konusunda bilgilendirilmelidir. Örneğin, yaşlı istismarı durumunda gizlilik göz ardı edilerek ilgili otoritelere istismarı bildirme gerekliliği vardır. Bu nedenle, ileri yetişkine gizliliğin sınırları konusunda gerekli bilgiler verilmelidir, bu sayede kişinin, maruz kaldığı istismar konusunda psikoloğa açılmasının sonuçlarını önceden bilmesi sağlanır (Welfel, Danzinger ve Santora, 2000).

Gizlilik konusundaki etik ikilemler, özellikle bilişsel bozukluğu olan ve kendine ya da başkalarına zarar verme olasılığı olan ileri yetişkinler söz konusu olduğunda ortaya çıkmaktadır (APA, 2004; 2014). Bilișsel bozukluğu olan ileri yetişkinlere mümkün olduğunca gizliliğin sınırları anlatılmalıdır. Bunun yanında velayet sahibine de gizliliğin hangi durumlarda göz ardı edilebileceğine yönelik bilgi verilmelidir (Zeranski ve Halgin, 2011).

İleri yetişkine bakım veren kişiler veya aile üyeleri, ileri yetişkin hakkında bilgi edinmek isteyebilirler. Bunun sebebi de çoğunlukla bu kişilerin ileri yetişkinin durumu hakkında endişe duymaları ya da ileri yetişkinin belirli davranışlarını anlamlandırmakta zorlanmalarıdır (Huq ve Mclntosh, 2015). Aile üyelerinin ya da ileri yetişkinle ilgilenen diğer profesyonellerin, ileri yetişkinle ilgili bilgi edinmek istedikleri durumlarda psikoloğun daha genç danışanlarına sağladığı tam gizliliği ileri yetişkinlere de sağlaması gerekmektedir. Ancak bilgi paylaşımı gerekliyse ya da yararlı olacağı düşünülüyorsa danışandan bu konuda izin almalıdır (Knight, 2004, akt. APA, 2014). Ayrıca uzun süreli kurum bakımı altında olan ileri yetişkinlerle çalışan psikologlar, görüşme yapılacak özel bir odanın yokluğu gibi problemler nedeniyle gizliliği koruma konusunda bazı zorluklarla karşılaşabilirler. Bu gibi durumlarda psikolog, gizliliğin korunabilmesi için gerekli önlemleri (örn., hemşirelerin seans sırasında içeriye girmemelerini istemek) almalı ve diğer sağlık çalışanlarıyla da bilgi paylaşımında bulunurken, gizliliğin sınırlarını ve ileri yetişkinin haklarını göz önünde bulundurmalıdır (Lichtenberg ve ark., 1998).

Huzurevi ve yaşlı bakım merkezlerinde yaşayan ileri yetişkinlerin genel olarak mahremiyete oldukça fazla değer verdikleri bu nedenle de araştırmaya katılmaya istekli olmayabilecekleri belirtilmektedir. Bu nedenle araştırmacı, araştırmaya katılmayı kabul eden katılım- cılara çalışmanın her aşamasında gizlilik ilkesinin takip edileceğini vurgulayarak belirtmelidir (O'Hara, Higgins, D'Andrea, Kennedy ve Dolores Gallagher-Thompson, 2003). İleri yetişkinlerle araştırma yapan psikologlar araştırmayı hastane, bakım evi ya da katılımcının evi gibi farklı yerlerde yürütmek durumunda kalabilir. Bu durumlarda da gizliliği korumaya yönelik ek önlemler almalıdır (Coon et al., 1999 akt. O'Hara ve ark., 2003). Örneğin, kurum bakımındaki ileri yetişkinlerle araştırma yürüten psikologlar araştırmanın amaç ve bağlamı doğrultusunda ileri yetişkinlerden alınan bilgilerin kurum yöneticileri, çalışanları ve sakinlerine ulaşmaması için özel önlemler almalıdırlar. Kurum çalı̧sanlarıyla bilgi paylaşımı gerekli görüldügünnde ise ileri yetişkinin kendisinden ya da velayet sahibinden izin alınmalıdır (High ve Doole, 1995).

\section{Yaşıı İstismarı}

İleri yetişkinlerle çalışan psikologları ilgilendiren konulardan bir diğeri de yaşlı istismarı ve ihmalidir (McGuire, 2009; Zeranki ve Halgin, 2011). TPD Etik Yönetmeliği'nde bu konuyu doğrudan ele alan etik standart bulunmamaktadır. Schweibert ve arkadaşlarının (2000) da belirttiği gibi etik yönetmeliklerin tüm durumları içeren kapsayıcılıkta olmasının mümkün olmadığı düşünüldüğünde bu durum anlașılabilir. Fakat özellikle ileri yetişkinlere psikolojik hizmet sunan ya da onlarla araştırma yürüten psikologların yaşlı istismarı vakalarıyla karşılaşma olasılıklarının yüksek olduğu bilinmektedir. $\mathrm{Bu}$ nedenle bu yazıda yaşlı istismarı konusu ayrı bir başlıkta ele alınarak hem bu konuya dikkat çekmek hem de psikologların yaşlı istismarı ile karşılaştıklarında nasıl bir yol izleyebileceklerine yönelik rehberlik sağlamak amaçlanmıştır.

Yaşlı istismarının oldukça yaygın olduğu, çoğunlukla aile içinde meydana geldiği ve çoğu zaman rapor edilmediği belirtilmektedir (örn., Beaulieu ve Leclerc, 2006; Schweibert ve ark., 2000; Welfel ve ark., 2000). Türkiye'de Aydın ilinde çok basamaklı örnekleme yöntemiyle yapılan bir çalışmada herhangi bir yaşlı istismar1 ya da ihmaline maruz kalan ileri yetişkinlerin oranı \%14.2'dir (Ergin ve ark., 2012). İzmir ilinde yapılan bir çalışmada da oranların benzer olduğu görülmektedir (örn., psikolojik ve fiziksel istismar için oranlar surasıyla \%9.4 ve \%8.2'dir; Kıssal ve Beşer, 2011). Bu sonuçların öz bildirime dayalı olması sebebiyle, özellikle cinsel istismar gibi bir durum söz konusu olduğunda aslında bu oranların rapor edilenden daha yüksek olduğu tahmini yapılabilir. Yaşlı istismarının yaygın bir olgu olduğu göz önünde bulundurulduğunda, psikologların yaşlı istismarı ile karşılaşma olasılıklarının tahminlerinin üstünde olduğu söylenebilir. Yaşlı istismarını saptamada psikososyal ve tıp gibi alanlarda hizmet veren profesyonellerin 
önemli bir rolü olduğu düşünüldüğünde (Beaulieu ve Leclerc, 2006), psikologların yaşlı istismarı ve bu konuda ortaya çıkabilecek etik ikilemler konusunda bilgi sahibi olmaları önem taşımaktadır.

Birçok ülkede olduğu gibi Türkiye'de de yaşlı istismarını ilgili kurumlara rapor etmek yasal bir zorunluluktur ve Türk Ceza Kanunu'nda istismar rapor edilmediği takdirde hapis ve adli para cezası verileceği belirtilmektedir (Madde 98, Türk Ceza Kanunu, 2004). Bu konuyla ilgili TPD Etik Yönetmeliği'nde (2004) danışan, kendine ya da başkalarına zarar veriyorsa veya verme olasılığı varsa ya da kötüye kullanıma maruz kalıyorsa, psikoloğun gizliliği göz ardı edebileceği belirtilmektedir. Bu nedenle, psikoloğun tespit ettiği ya da şüphelendiği yaşlı istismarı ya da ihmalini rapor etmesi etik bir sorumluluktur. Bunlara ek olarak, Zeranski ve Halgin'in (2011) belirttiği gibi, APA'nın (2004; 2014) ilgili kılavuzunun 18. ve 19. maddeleri yaşlı istismarı çerçevesinde ele alınabilir. Bu maddelerde psikoloğun yaşlı istismarı ile karşılaştığında ne yapması gerektiği ve bu konuda hangi alanlarda bilgi sahibi olması gerektiğine değinilmektedir. Ayrıca psikoloğun, ileri yetişkinlik döneminde bireylerin kullanabilecekleri kaynaklar konusunda bilgi sahibi olması ve bu sayede gerektiği durumlarda ilgili yönlendirmeleri yapabilecek yetkinliğe sahip olması teşvik edilmektedir. Özetlemek gerekirse, psikologlar, karşılaştıkları yaşlı istismarı vakalarını hem yasal hem de etik sebeplerle (örn., yararlı olmak ve zarar vermemek) rapor etmekle yükümlüdürler. Bu noktada, yaşlı istismarını rapor etmek için kanıta sahip olma zorunluluğunun olmadığını, istimara yönelik şüphe oluşturan bir durum söz konusu ise ilgili birimlere başvurulması gerektiğini hatırlatmak önemli olabilir (Dong, 2015).

Yaşlı istismarının açık olduğu durumlarda (örn., fiziksel şiddet, terk etme) istismarı fark etmek ve rapor etmek kolayken görece daha az belirgin olan durumlarda zordur (Zeranski ve Halgin, 2011; Welfel ve ark., 2000). Zor fark edilen yaşlı istismarı türleri, risk faktörleri, istismarı fark etmeye yönelik ipuçları ve söz konusu istismar durumlarında hem klinik hem de yasal açıdan ne yapılması gerektiği gibi konularda psikologların bilgi sahibi olmaları son derece önemlidir (McGuire, 2009; Zeranski ve Halgin, 2011). Ancak psikolojik hizmet sunan profesyonellerin istismar durumlarında nasıl bir yol izleyecekleri konusunda kararsızlık yaşayabilecekleri ve ilgili yasa ve etik ilkeleri nasıl yorumlayacakları konusunda zorlanabilecekleri belirtilmektedir (Zeranski ve Halgin, 2011; Welfel ve ark., 2000). Bu noktada, psikolog istismar durumu ya da şüphesinde daha iyi bir değerlendirme yapabilmek için bu konuda uzman olan meslektaşlarına danışabilir (Welfel ve ark., 2000). Ayrıca Welfel ve arkadaşları (2000), özellikle bakımı başkaları tarafından karşılanan (örn., aile üyeleri, akrabalar) ileri yetişkinlere ya da ileri yetişkinlere bakım veren kişilere hizmet veren psikologların, yaşlı istismarı konusunda daha dikkatli olmaları gerektiğini belirtmektedirler. Buna ek olarak, psikoloğun problemler hakkında konuşurken istismarı açıklamayı kolaylaştırması nedeniyle yargılayıcı olmadan, güven verici, destekleyici ve empatik bir atmosfer oluşturmasını önermektedirler.

Yaşlı istismarı konusunda psikologların yaşadıkları en önemli etik ikilemlerden biri istismarı rapor etme ve terapötik ilişkiye zarar vermeme arasındadır. Bir başka deyişle, yasal ve etik sorumluklar ile klinik ihtiyaç ve yararlar arasında yaşanan ikilemdir (Zeranki ve Halgin, 2011). Welfel ve arkadaşları (2000), söz konusu ilişkinin devam ettirilebilmesinde dikkatli olunması gereken bazı noktalara değinmiştir: Öncelikle, acil rapor gerektirmeyen durumlarda danışan, istismarın rapor edileceği konusunda bilgilendirilmeli ve rapor etme sürecinde daha aktif bir rol oynaması için cesaretlendirilmelidir. Bunun yanı sıra, danışan rapor etme sürecinin pratik ve duygusal açıdan nasıl ilerleyeceği konusunda bilgilendirilebilir. Böylece danışanın bu konudaki korkusu ve yanlış düşünceleri azaltılarak terapötik ilişskinin devam ettirilmesi sağlanabilir. Buna ek olarak görüşmelerde istismarın rapor edilmesi konusunda kızgın olan danışanın olumsuz duyguları ele alınarak söz konusu ilişsinin zarar görmesi engellenmeye çalışılabilir. Ayrıca danışanla ilgili tüm bilgilerden ziyade sadece ilgili bilgilerin gerekli otoritelere sunulması ve rapor sonrasında ileri yetişkine gerekli hizmetlerin sunulup sunulmadığının takip edilmesi gerekmektedir (Welfel ve ark., 2000).

İleri yetişkinler, özellikle istismarcı kendi çocuğuysa, çocuklarına çeşitli yaptırımlar uygulanmasını önlemek için ya da terkedilmekten/cezalandırılmaktan/ kurum bakımına alınmaktan korktukları ve yaşam koşullarının daha da kötüleşeceğini düşündükleri için maruz kaldıkları istismarın rapor edilmesini reddedebilmektedirler (Schweibert ve ark., 2000; Welfel ve ark., 2000). $\mathrm{Bu}$ gibi durumlar, özerk hareket etme konusunda işlevselliğini sürdüren ya da bir dereceye kadar devam ettiren ileri yetişkinlerin isteklerine karşı çıkmayı gerektirmektedir. Böyle durumlarda psikolog, danışanın özerkliğine saygı duyma ile danışana yararlı olma ve zarar vermeme arasında etik ikileme düşebilir (Scheiderer, 2012). Ayrıca aile üyeleri de ailenin itibarını düşünerek istismarın rapor edilmesine karşı çıkabilmektir (Welfel ve ark., 2000). Yaşlı istismarı faillerinin oldukça yüksek bir oranının ileri yetişkinlerin yetişkin çocukları olduğu göz önünde bulundurulduğunda (Welfel ve ark., 2000), psikoloğun bu tür durumlarla karş1laşma ve etik ikileme düşme olasılığ1 yüksektir. Özellikle böyle durumlarda psikoloğun, ileri yetişkine maddi destek, barınma ve evde bakım hizmeti sağlama gibi konularda doğru yönlendirmeyi yapabilecek donanımda olması gerekmektedir (Schwe- 
ibert ve ark., 2000; Welfel ve ark., 2000). Bunun yanı sıra, ileri yetişkini istismar eden yetişkin çocukları ile de görüşerek, bu kişilerin ebeveynlerine bakım verme konusundaki duygu ve düşünceleri hakkında konuşabileceği ve ebeveynleriyle olan ilişkilerini güçlendirebilmek adına onları ebeveynleriyle birlikte seanslara katılmaya davet edebileceği ayrıca bu kişilere daha etkili baş etme stratejilerini öğretebileceği belirtilmektedir (Schweibert ve ark., 2000). Tüm bu süreçlerde gerekli görüldüğünde diğer meslektaşlara danışmanın ileri yetişkin için en iyisine karar vermede önemli bir rehberlik sağlayabileceği de unutulmamalıdır (Zeranski ve Halgin, 2011).

\section{Sonuç}

İleri yetişkinlere psikolojik hizmet veren ve ileri yetişkinlerle araştırma yürüten psikologların (ya da psikolojik danışmanların) dikkat etmesi gereken pek çok etik konu olduğu görülmektedir (örnekler için bkz. Tablo 1). Öncelikle ileri yetişkinlere yeterli bir şekilde hizmet verebilmek ya da araştırma yapabilmek için gerekli olan ek bilgi ve becerilerin kazanılması ve eğitim alınması gerekliliği önemle vurgulanan bir noktadır (Karel, 2011; Knight ve ark., 2009; Molinari ve ark., 2003; Qualls ve ark., 2002). Bunun yanı sıra öne çıkan diğer etik konular ileri yetişkinin özerkliğine saygı duyma, gizliliği koruma ve gizliliğin sınırları, bilgilendirilmiş onam almada dikkat edilecek hususlardır. Yaşlı istismarının da ileri yetişkinlerle çalışan psikologları oldukça yakından ilgilendiren bir konu olduğu ve psikologların ilgili yasal düzenlemeler ve etik konulara hakim olmalarının oldukça önemli olduğu belirtilmektedir (McGuire, 2009; Zeranski ve Halgin, 2011).

$\mathrm{Bu}$ makalede alanyazında öne çıkan, ileri yetişkinlerle çalışan psikologların karşılaşabilecekleri belirli etik konular çeşitli önerilerle birlikte ele alınmış ve bu konulardaki etik farkındalığın artırılması amaçlanmıştır. Dolayısıyla bu derleme yazısının, ileri yetişkinlere psikolojik hizmet veren ve onlarla araştırma yürütenlere katkısının olması beklenmektedir. İlgili alanyazında doğrudan bu konu ile ilintili kaynakların yok denecek kadar az olduğu göz önünde bulundurulduğunda bu metnin söz konusu bu boşluğu doldurmada atılan adımlardan biri olduğu söylenebilir. 
Tablo 1. Etik İlke/Standartlara Uygun Hareket Edilmediği Durumda Çıkabilecek Sorunlarla İlgili Örnekler

\begin{tabular}{|c|c|}
\hline ETİK İLKE/STANDART & Örnekler \\
\hline Yeterlik & $\begin{array}{l}\text { - Yaşlanma konusunda yeterli bilgiye sahip olmayan ve ileri yetişkinlerin psikolojik ve fiziksel } \\
\text { işlevsellik açısından oldukça heterojen bir yaş grubu olduğunun farkında olmayan bir psikolog, psi- } \\
\text { kososyal terapilerin bu yaş grubunda pek de etkili olmayacağını ve bazı değişiklikler için çok geç bir } \\
\text { yaş olduğunu düşünebilir. Dolayısıyla aslında etkili olabilecek müdahaleleri uygulamayabilir (bkz. } \\
\text { APA, 2014). } \\
\text { - İleri yetişkinlere yönelik olumsuz kalıp yargıların farkında olunmaması, yanlış teşhisler } \\
\text { koymaya ya da belirli semptomların hastalıktan ziyade yaşlanmaya yüklenmesine neden olabilir. } \\
\text { Örneğin, psikolog, uyuşukluk ve iştahta azalma gibi depresif belirtiler rapor eden bir ileri yetişkinin bu } \\
\text { belirtilerini yaşlanmanın doğal bir sonucu olduğunu düşündüğü için depresyon teşhisi koymayabilir } \\
\text { (bkz. APA, 2014). }\end{array}$ \\
\hline Özerklik & $\begin{array}{l}\text { - Tek başına yaşayan ileri yetişkin bir danışan ve aile üyelerinin, ileri yetişkinin bağımsız ya- } \\
\text { şaması konusundaki görussleri çatıştı̆ında psikolog, (danışan günlük işlerini güvenli bir şekilde ger- } \\
\text { çekleştiremediği için) danışanına güvenliği için ailesinin bu konudaki isteklerine uymasını önerebilir. } \\
\text { Bu durumda, psikolog evde koruyucu birtakım fiziksel önlemler alınarak danışanın daha güvenli bir } \\
\text { şekilde yaşayabileceği seçeneğini göz ardı ederek özerk karar verme kapasitesi yerinde olan danışanın } \\
\text { özerkliğini korumamış olur (bkz., Fitting, 1986; Schwiebert ve ark., 2000). } \\
\text { • Aile üyeleri tarafindan psikoterapi için getirilen bir ileri yetişkin, aile üyelerinin zorlaması } \\
\text { ile psikoloğa gelmiş olabilir. Psikolog, danışanın aile üyelerinin kararından bağımsız olarak terapiye } \\
\text { katılmak isteyip istemediğini anlamaya çalışmadığı durumda danışanın özerkliğine saygı duymamış } \\
\text { olur (bkz., APA, 2014). }\end{array}$ \\
\hline Bilgilendirilmiş Onam & $\begin{array}{l}\text { - Demans tanısı almış ileri yetişkinlere hizmet veren ya da bu kişilerle araştırma yapan bir psi- } \\
\text { kolog, kişilerin karar verme kapasitelerinin yeterli olup olmadığına yönelik gerekli değerlendirmeleri } \\
\text { yapmadan sadece tanıya dayanarak bu kişilerin kendisinden onam almaya gerek görmeyebilir. Bu } \\
\text { durumda psikolog, özellikle bilişsel işlevselliği onam verme konusunda henüz yeterli olan kişilerin } \\
\text { özerkliğine saygı duymamış olur (bkz. APA, 2014). } \\
\text { - Psikolog, yürüttüğü araştırma için ileri yetişkinlerden bilgilendirilmiş onam alırken araştırma } \\
\text { kapsamında herhangi bir tedavi verilmeyeceğini belirtmediğinde, bazı ileri yetişkinler (özellikle eve } \\
\text { bağımlı ileri yetişkinler) yapılan araştırma sırasında bir tür tedavi ya da bakım alacaklarını düşünebilir } \\
\text { ve araştırmaya katılmayı bu nedenle kabul edebilir (bkz., Locher ve ark., 2006). }\end{array}$ \\
\hline Gizlilik & $\begin{array}{l}\text { - İleri yetişkin kadın bir danışanı olan bir psikolog, annesini terapiye getirip götüren danışanının } \\
\text { kızının yoğun bir şekilde ısrar etmesi üzerine ve ileri yetişkinin yararına olacağını düşünerek kızıyla } \\
\text { bazı bilgileri paylaşabilir. Bu durumda psikolog, danışanın iznini almadan böyle bir bilgi paylaşımın- } \\
\text { da bulunduğu için gizlilik ilkesini ihlal etmiş olur (bkz. APA, 2014). } \\
\text { • Kurum bakımı altında olan ileri yetişkin danışanları olan bir psikoloğun, görüşme için ayrı- } \\
\text { lan özel bir yer olmaması ve kurum çalışanlarını görüşme sirasında odaya girmemeleri konusunda } \\
\text { uyarmaması nedeni ile görüşme sırasında odaya giren kurum çalışanları konuşulanların bir kısmını } \\
\text { duyabilir. Bu durumda psikolog gizlilik ilkesini ihlal etmiş olur (bkz., Lichtenberg ve ark., 1998). }\end{array}$ \\
\hline Yaşlı İstismarı & $\begin{array}{l}\text { - Evde görüşme tekniği ile veri toplayan bir psikolog, görüşme sırasında ileri yetişkin bir katı- } \\
\text { lımcının evdeki bazı bireyler tarafından istismar edildiğini fark edebilir. Katılımcıya, bu durumu rapor } \\
\text { etme gerekliliğini belirtmesine rağmen katılımcının 1srarları üzerine istismarı rapor etmeyebilir. Bu } \\
\text { durumda psikolog istismarı rapor etme etik ve yasal sorumluluğunu ihmal etmiş olur (bkz., Schweibert } \\
\text { ve ark., 2000; Zeranski ve Halgin, 2011; Welfel ve ark., 2000). } \\
\text { - Oğlu ile birlikte yaşayan ileri yetişkin bir danışanın, oğlu tarafından istismara uğradığını öğre- } \\
\text { nen bir psikolog, bu gibi durumlarda sağlanan maddi destek, barınma ve evde bakım hizmeti sağlama } \\
\text { gibi konularda yeterli bilgisi olmadığı için bu konularda danışanına gerekli bilgilendirme ve yönlen- } \\
\text { dirmeyi yapamayabilir (bkz., Schweibert ve ark., 2000; Welfel ve ark., 2000). }\end{array}$ \\
\hline
\end{tabular}




\section{Kaynaklar}

American Psychological Association Working Group on the Older Adult (N. Abeles, S. Cooley, I. M. Deitch, M. Harper, G. Hinrichsen, M. Lopez ve V. Molinari) (1998). What practitioners should know about working with older adults. Professional Psychology: Research and Practice, 29, 413-427.

American Psychological Association (2004). Guidelines for psychological practice with older adults. American Psychologist, 59, 236-260.

American Psychological Association. (2014). Guidelines for psychological practice with older adults. American Psychologist, 69, 34-65.

Barnett, J. E. ve Quenzel, A. P. (2017). Innovating to meet the needs of our aging population. Practice Innovations, 2, 136-149.

Beaulieu, M. ve Leclerc, N. (2006). Ethical and psychosocial issues raised by the practice in cases of mistreatment of older adults. Journal of Gerontological Social Work, 46, 161-186.

Beck, C. ve Shue, V. (2003) Surrogate decision making and related issues. Alzheimer Disease and Associated Disorders, 17,12-16.

Bush, S. S., Allen, R. S., Heck, A. L. ve Moye, J. (2015). Ethical issues in geropsychology: Clinical and forensic perspectives. Psychological Injury and Law, 8, 348-356.

Charles, S. T. ve Carstensen, L. L. (2010). Social and emotional aging. Annual Review of Psychology, 61, 383-409.

Çakmak, Z. (2018). Çocukların katılımıyla yürütülen araştırmalarda etik. Türk Psikoloji Yazıları, 21, 30-37.

Değirmencioğlu, S. M. ve Demirutku, K. (1999). Öğretim üyesi ve öğrenci işbirliği ile hazırlanan yayınlarda yazarlık hakkının ve sırasının belirlenmesinde yardımcı olabilecek öneriler. Türk Psikoloji Dergisi, 14, 111-119.

Dong, X. Q. (2015). Elder abuse: systematic review and implications for practice. Journal of the American Geriatrics Society, 63, 1214-1238.

Erber, J. T. (2013). Aging and older adulthood. West Sussex: John Wiley \& Sons.

Ergin, F., Evci-Kiraz, E. D., Saruhan, G., Benli, C., Okyay, P. ve Beser, E. (2012). Prevalence and risk factors of elder abuse and neglect in a western city of Turkey: A community based study. Bulletin of theTransylvania University of Braşov Series VI: Medical Sciences, 5, 33-50.

Ertan Kaya, Ö. (2017). Nörogörüntüleme çalışmalarında etik meseleler. Türk Psikoloji Yazıları, 20, 39-48.

Eskin, M. (2000). Klinik psikolojide etik uygulamalar. Türk Psikoloji Yazıları, 15, 81-83.
Fitting, M. D. (1986). Ethical dilemmas in counselling elderly adults. Journal of Counselling and Development, 64, 325-327.

Guzey, M. (2007). Araştırma etiğinin bir başka boyutu: Yazarlık hakkının etik açıdan değerlendirilmesi. Türk Psikoloji Bülteni, 41, 16-19.

High, D. M. ve Doole, M. M. (1995). Ethical and legal issues in conducting research involving elderly subjects. Behavioral Sciences and the Law, 13, 319-335.

Hoge, M. A., Karel, M. J., Zeiss, A. M., Alegria, M. ve Moye, J. (2015). Strengthening psychology's workforce for older adults: Implications of the Institute of Medicine's report to Congress. American Psychologist, 70, 265-278.

Huq, A. ve McIntosh, M. (2015). Professional and ethical issues in working with older adults. R. Tribe ve J. Morrissey (Ed.), Handbook of professional and ethical practice for psychologists, counsellors and psychotherapists içinde (s. 197-207). New York, NY: Routledge.

Karel, M. J. (2011). Ethics. V. Molinari (Ed.), Specialty competencies in geropsychology içinde (s. 115142). New York: Oxford University Press.

Karel, M. J., Emery, E., Molinari, V. ve CoPGTPTask Force on the Assessment of Geropsychology Competencies (2010). Development of a tool to evaluate geropsychology knowledge and skill competencies. International Psychogeriatrics, 22, 886-895.

Kissal, A. ve Beşer, A. (2011). Elder abuse and neglect in a population offering care by a primary health care center in Izmir, Turkey. Social Work in Health Care, 50, 158-175.

Knight, B. G., Karel, M. J., Hinrichsen, G. A., Qualls, S. H. ve Duffy, M. (2009). Pikes Peak model for training in professional geropsychology. American Psychologist, 64, 205-214.

Korkut, Y., Müderrisoğlu, S. ve Tanık, M. (2006). Klinik psikoloji alanında karşılaşılan etik ihlal örnekleri ve nasıl ele alındıklarının değerlendirilmesi. Türk Psikoloji Yazıları, 9, 49-61.

Köse, B. (2007). Panel: Sinemada psikoterapistler ve psikoterapi etiği. Türk Psikoloji Bülteni, 41, 1-15.

Lichtenberg, P. A., Smith, M., Frazer, D., Molinari, V., Rosowsky, E., Crose, R., ... Salamon, M. (1998). Standards for psychological services in long-term care facilities. The Gerontologist, 38, 122-127.

Locher, J. L., Bronstein, J., Robinson, C. O., Williams, C. ve Ritchie, C. S. (2006). Ethical issues involving research conducted with homebound older adults. The Gerontologist, 46, 160-164.

McGuire, J. (2009). Ethical considerations when working with older adults in psychology. Ethics \& Behavior, 19, 112-128. 
Molinari, V., Karel, M., JonesSr, S., Zeiss, A.,Cooley, S G., Wray, L., ...Gallagher-Thompson, D. (2003). Recommendations about the knowledge and skills required of psychologists working with older adults. Professional Psychology: Research and Practice, 34, 435-443.

Oakland, T., Leach, M. M., Bartram, D., Lindsay, G., Smedler, A. C. ve Zhang, H. (2012). An international perspective on ethics codes in psychology. M. M. Leach, M. Stevens, A. Ferrero, Y. Korkut, ve G. Lindsay (Ed.), Handbook of international psychological ethics içinde (s. 19-27). New York, NY: Oxford University Press.

O’Hara, R., Higgins, A. B., D’Andrea, J. A., Kennedy, Q. ve Gallagher-Thomson, D. (2003). Research with older adults. J. C. Thomas ve M. Hersen (Ed.), Understanding Research in Clinicial and Counselling Psychology içinde (s. 441-467). Mahvway, New Jersey: Lawrence Erlbaum Associates.

Qualls, S. H., Segal, D. L. ve Hiroto, K. E. (2015). Special issues in working with older adults. J. R. Matthews ve E. C. Walker (Ed.), Your practicum in psychology: A guide for maximizing knowledge and competence içinde (2. bask1, s. 203-223). Washington, DC: American Psychological Association.

Qualls, S. H., Segal, D. L., Norman, S., Niederehe, G. ve Gallagher-Thompson, D. (2002). Psychologists in practice with older adults: Current patterns, sources of training, and need for continuing education. Professional Psychology: Research and Practice, $33,435-442$.

Resau, S. (1995). Obtaining informed consent in Alzheimer's research. Journal of Neuroscience and Nursing, 27, 57-60.

Sayıl, M. ve Yılmaz, A. (2001). Gelişim psikolojisi araştırmalarında etik standartlar ve tartışılan sorunlar. Türk Psikoloji Dergisi, 16, 71-78.

Schaie, K. W. (1996). Intellectual development in adulthood: The Seattle longitudinal study. New York: Cambridge University Press.

Scheiderer, E. M. (2012). Elder abuse: Ethical and related considerations for professionals in psychology. Ethics \& Behavior, 22, 75-87.

Schwiebert, V. L., Myers, J. E. ve Dice, C. (2000). Ethical guidelines for counselors working with older adults. Journal of Counseling \& Development, 78, 123-129.

Sümer, C. (1998). Türkiye'de psikoloji uygulama, araştırma ve yayımlarında etik ilkeler: Tartışma I. Türk Psikoloji Dergisi, 13, 77-79.

Türk Ceza Kanunu (TCK, 2004). Erişim Tarihi: 30 May1s 2016, http://www.mevzuat.gov.tr/MevzuatMetin/1.5.5237.pdf
Türk İstatistik Kurumu (TÜİK). Yaş ve cinsiyete göre nüfus, 2013-2075, Erişim Tarihi: 30 Mayıs 2016, http://www.tuik.gov.tr/UstMenu.do?metod=temelist

Türk İstatistik Kurumu (TÜİK). Illere ve cinsiyete göre doğuşta beklenen yaşam süreleri, 2013-2014, Erişim Tarihi: 30 Mayıs 2016, http://www.tuik.gov.tr/ UstMenu.do?metod = temelist

Türk Psikologlar Derneği (2004). Türk Psikologlar Derneği Etik Yönetmeliği. Erişim Tarihi: 30 Mayıs 2016, https://www.psikolog.org.tr/turkey-code-tr. pdf

Türk Psikologlar Derneği (1999). Afet bölgelerinde yapılan psikoloji araştırmalarında uyulması gereken etik ilkeler. Türk Psikoloji Dergisi, 14, 87-88.

Welfel, E. R., Danzinger, P. R. ve Santoro, S. (2000). Mandated reporting of abuse/maltreatment of older adults: A primer for counselors. Journal of Counseling \& Development, 78, 284-292.

Woods, B. ve Pratt, R. (2005). Awareness in dementia: Ethical and legal issues in relation to people with dementia. Aging \& Mental Health, 9, 423-429.

Zeranski, L. ve Halgin, R. P. (2011). Ethical issues in elder abuse reporting: A Professional psychologist's guide. Professional Psychology: Research and Practice, 42, 294-300. 


\title{
Summary \\ Ethical Issues Needed to Be Paid Attention by Psychologists Working with Older Adults
}

\author{
Şule Selçuk \\ Kastamonu University
}

Ethical principles in psychology provide shared values for psychologists and guide them in professional life (TPD Code of Ethics, 2004). However, Turkish Psychological Association (TPD) Code of Ethics (2004) does not involve specific ethical standards for psychologists working with older adults (i.e., psychologists providing psychological services and/or conducting research with older adults). Similarly, though APA published guidelines for these psychologists, APA Code of Ethics (2002) also does not cover such ethical standards. Moreover, to the best of our knowledge, there is no published work in Turkey that is directly related with ethical issues regarding working with older adults. Therefore, the aim of the present review is to fill this gap in the literature by covering ethical issues needed to be paid attention by psychologists working with older adults.

It is known that life expectancy has increased over time and it is estimated that the percentage of older population will continue to increase (see Turkish Statistical Institute, 2013). Hence, interest in research conducted with older adults and the number of psychologists who provide psychological services to them gradually increase (see American Psychological Association Working Group on the Older Adult, 1998). Therefore, it is quite important to increase awareness about ethical issues regarding working with older adults. To this end, in the present review, ethical issues related to competence, autonomy, informed consent, confidentiality, and older adult abuse were covered, respectively.

\section{Competence}

Psychologists working with older adults need additional knowledge and skills to serve competently (Karel, 2011). For instance, it is important for psychologists to know that older adults are not homogenous in terms of functioning. (see Erber, 2013). Therefore, researchers suggested to divide older adulthood into three categories: young-old (65-74), old-old (75-84), and oldest-old age ( 85 and older). Among these age groups, oldest-olds are more likely to experience cognitive decline and chronic health problems so they need related services more (Erber, 2013). Psychologists may be more likely to serve competently to young-olds since individuals in this age group has similar characteristics with younger people. However, clinical or counselling education and training for adult clients may not be sufficient to serve old-olds and oldest-olds competently. Thus, it seems that related psychologists should gain additional knowledge and skills for older adults (Knight, Karel, Hinrichsen, Qualls, \& Duffy, 2009; Molinari et al., 2003; Qualls, Segal, Norman, Niederehe, \& Gallagher-Thompson, 2002).

A survey study conducted with APA members revealed that more than half of the psychologists who already provide psychological services and wish to serve more to older adults, reported that they need additional education and training (Qualls et al., 2002). Based on this study, it is suggested for related psychologists to get additional knowledge regarding characteristics and the effects of aging, common difficulties and treatments in older adulthood, and to receive additional training and supervision (APA 2004; 2014; McGuire, 2009; Qualls et al., 2002). In addition, it is suggested that education opportunities in geropsychology should be improved. (Bush, Allen, Heck, \& Moye, 2015).

In 2004, APA published "Guidelines for Psychological Practice with Older Adults" that involves aspirational goals rather than standards (the guidelines were updated in 2014). Some suggestions for psychologists in the guidelines are: (a) to be aware of the individual differences among older adults, (b) to know related measurement instruments for this age group, and (c) to be aware of one's own attitudes regarding older adults (APA, 2004; 2014). In addition, it is suggested for related psychologists to know normative and nonnormative changes, common health problems (e.g., arthritis) and medications in older adulthood in order to correctly de-

Address for Correspondence: Res. Asst. Şule Selçuk, Kastamonu University, Faculty of Science and Literature, Department of Psychology, Kuzeykent Campus, 37150, Kastamonu.

E-mail: sselcuk@kastamonu.edu.tr 
fine the reasons behind the problems (physical vs. psychological) (Barnett \& Quenzel, 2017). Another widely cited resource that is suggested for psychologists working with older adults is The Pikes Peak model (Knight et al., 2009). It involves a comprehensive set of information about attitudes, knowledge, and skills that are important to serve competently (Knight et al., 2009).

\begin{abstract}
Autonomy
One of the common ethical dilemmas of psychologists working with older adults is between the principle of autonomy and benficence/nonmaleficence, and between the principle of autonomy and protecting the psychologist-client relationship (Bush et al., 2015; Fitting, 1986; Karel, 2011). These ethical dilemmas emerge especially when there is an impairment in the older adult's functioning (mostly in cognitive functioning) and severe (e.g. major depression) or fatal disease since these factors influence the decision making ability regarding their own safety and wellbeing (APA, 2004; Fitting, 1986; Karel, 2011; Schwiebert, Myers, \& Dice, 2000; Woods $\&$ Pratt, 2005). Therefore, it should be noted that older adults' decision making competence should be evaluated repeatedly and monitored periodically (Scheiderer, 2012). However, it should also be kept in mind that a large number of older adults preserve their decision making ability to a great extent (Karel, 2011).

One of the common ethical dilemmas regarding older adults living in long-term care settings emerges when the older adult wants to live independently whereas the family members insist long-term care for the older adult (APA, 2004; 2014). Since living independently may put safety of other people and the older adult at risk, the psychologist confronts with an ethical dilemma between providing safety/avoiding harm and preserving the client's autonomy. In such situations, psychologists should ensure maximum autonomy for the older adult while minimizing the possibility of harm (Schwiebert et al., 2000). Fitting (1986) suggest that when there is a conflict between the wishes of the older adult and the family members, the psychologist may talk with the older adult and the family members together in order to evaluate family relations and asses the conflict in a context of family system. For instance, if the client has sufficient decision-making capacity, then some alternative solutions may be found (e.g., taking some safety precautions in the older adult's house such as moving throw rugs away) (Fitting, 1986).
\end{abstract}

\section{Informed Consent}

Psychologists should pay additional attention to whether the older adult fully understands the research purposes or implications of the treatment (McGuire,
2009). It is especially difficult to decide whether the older adult is capable of giving informed consent when there is cognitive decline (Schwiebert et al., 2000). Therefore, psychologists may ask the older adult to repeat the information in informed consent in his/her own words" (Locher, Bronstein, Robinson, Williams, \& Ritchie; McGuire, 2009). If there is doubt regarding decision-making capacity of the older adult and the psychologist does not have sufficient expertise, then the psychologist may refer the client to another expert in order to evaluate his/ her decision-making skills (Molinari et al., 2003).

It is indicated that for older adults who are brought in for therapy by their family members, psychologists should ensure that attending the therapy is the older adult's autonomous decision (APA, 2002; 2014). In addition, TPD Code of Ethics (2002) communicates that psychologists are required to receive consent from legally authorized persons for individuals who are not legally capable of giving informed consent (e.g., if there is severe decline in specific skills). At this point, the psychologists should notice that there is no conflict of interest between the older adult and the legally authorized person (Beck \& Shue, 2003; Bush et al., 2005; Resau, 1995).

Psychologists conducting research with older adults should pay attention to additional requirements. For instance, they should clearly explain the older participants that no treatment will be provided within the scope of their research since especially homebound older adults may have such misconceptions (Locher et al., 2006). Moreover, homebound older adults may accept to participate in the research since they may think that they will more easily attain to health care or they may wish to please the health care providers. Therefore, it is suggested to apply a two-step consent process: Firstly, the health care providers receive consent from the potential participant before recommending him/her to the study. Next, researchers receive consent from those who accepted to be recommended for the research (Locher et al., 2006).

\section{Confidentiality}

Another set of ethical dilemmas is related with confidentiality. According to TPD Code of Ethics (2004), psychologists should inform the client regarding the limits of confidentiality beforehand so they can decide to take treatment or participate in the research accordingly. For instance, psychologists are required to report the abuse to related authorities. Therefore, they should inform older adults about this obligation so as they be aware of the consequences of disclosing the abuse to the psychologist (Welfel, Danzinger, \& Santora, 2000). Ethical dilemmas related to confidentiality arises especially 
when there is a serious cognitive decline or possibility of harm (APA, 2004; 2014). Psychologists should also inform older adults with cognitive decline (as much as possible) and the legally authorized person about the limits of confidentiality.

Psychologists are required to ensure full confidentiality to older adults as they provide to younger individuals. However, if it is necessary or beneficial to share specific information about the older adult with other professionals or family members, the psychologist should take permission from the older adult (Knight, 2004 cited in APA, 2014). Psychologists providing psychological services or conducting research with older adults living in long-term care settings should take additional precautions to protect confidentiality (e.g., asking the staff not to enter in the room during therapy sessions).

\section{Older Adult Abuse}

Ethical codes including TPD Code of Ethics do not include specific ethical standards regarding older adult abuse and neglect. However, psychologists especially working with older adults are highly likely to encounter with abuse cases given that older adult abuse is quite common (Beaulieu \& Leclerc, 2006; Welfel et al., 2000). Therefore, we also covered older adult abuse in the present review.

Different studies indicated that older adult abuse is quite common also in Turkey (Ergin et al., 2012; Kissal \& Beşer, 2011). Since psychologists and medical practitioners have important roles in identifying abuse (Beaulieu \& Leclerc, 2006), it is vital for psychologists to have knowledge about older adult abuse and related ethical dilemmas.

Reporting older adult abuse to authorities is a legal and ethical requirement in Turkey as in many countries. In addition, psychologists should know what steps required to be followed when they suspect or encounter abuse (APA, 2004; 2014). They should also have knowledge about the types and risk factors of older adult abuse and the hints for identifying it (McGuire, 2009; Zeranski \& Halgin, 2011).

One important ethical dilemma regarding older adult abuse is between reporting the abuse and protecting the therapeutic relationship (Zeranski \& Halgin, 2011). To maintain the therapeutic relationship, Welfel and colleagues (2000) suggested that older adults should be informed about the requirement to report the abuse and be encouraged to actively involve in the reporting process. In addition, they should be informed about what would be the emotional and practical consequences of reporting and their negative emotions regarding reporting should be addressed in the sessions (Welfel et al., 2000).
Especially when the abuser is the older adult's child or children, an ethical dilemma between the principle of autonomy and beneficence/nonmaleficence might emerge as the older adult is more likely to reject reporting the abuse (Schweibert et al., 2000; Welfel et al., 2000). In such cases, the psychologists should be able to guide the older adult regarding financial support opportunities, home care services, and shelter (Schweibert et al., 2000; Welfel et al., 2000).

\section{Conclusion}

There are many important ethical issues that are needed to be paid attention by psychologists working with older adults. This review addresses these ethical issues with some suggestions provided in the literature. As there is scarcity of resource that is directly related with this topic, the present review takes a step filling this gap in the literature. 